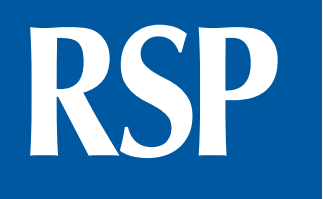

http://www.rsp.fsp.usp.br/

Revista de Saúde Pública

\title{
Multinomial model and zero-inflated gamma model to study time spent on leisure time physical activity: an example of ELSA-Brasil
}

\author{
Aline Araújo Nobre', Marilia Sá Carvalho', Rosane Härter Griep", Maria
Enirtes Caetano Prates Melo'"I, Itamar de Souza Santos' ${ }^{\prime V}$, Dora Chor"II \\ I Programa de Computação Científica. Fundação Oswaldo Cruz. Rio de Janeiro, RJ, Brasil \\ " Instituto Oswaldo Cruz. Fundação Oswaldo Cruz. Rio de Janeiro, RJ, Brasil \\ II' Escola Nacional de Saúde Pública. Fundação Oswaldo Cruz. Rio de Janeiro, RJ, Brasil \\ Iv Faculdade de Medicina. Universidade de São Paulo. São Paulo, SP, Brasil
}

Correspondence:

Aline Araújo Nobre

Av. Brasil, 4365 Manguinhos 21040-900 Rio de Janeiro, RJ, Brasil

E-mail: aline.nobre@fiocruz.br

Received: Dec 15, 2015

Approved: Jul 19, 2016

How to cite: Nobre AA,

Carvalho MS, Griep RH,

Fonseca MJM, Melo ECP,

Santos IS, et al. Multinomial model

and zero-inflated gamma model

to study time spent on leisure time

physical activity: an example of

ELSA-Brasil. Rev Saude Publica.

2017;51:76

Copyright: This is an open-access article distributed under the terms of the Creative Commons Attribution License, which permits unrestricted use, distribution, and reproduction in any medium, provided that the original author and source are credited.

\section{ABSTRACT}

OBJECTIVE: To compare two methodological approaches: the multinomial model and the zero-inflated gamma model, evaluating the factors associated with the practice and amount of time spent on leisure time physical activity.

METHODS: Data collected from 14,823 baseline participants in the Longitudinal Study of Adult Health (ELSA-Brasil - Estudo Longitudinal de Saúde do Adulto) have been analysed. Regular leisure time physical activity has been measured using the leisure time physical activity module of the International Physical Activity Questionnaire. The explanatory variables considered were gender, age, education level, and annual per capita family income.

RESULTS: The main advantage of the zero-inflated gamma model over the multinomial model is that it estimates mean time (minutes per week) spent on leisure time physical activity. For example, on average, men spent 28 minutes/week longer on leisure time physical activity than women did. The most sedentary groups were young women with low education level and income

CONCLUSIONS: The zero-inflated gamma model, which is rarely used in epidemiological studies, can give more appropriate answers in several situations. In our case, we have obtained important information on the main determinants of the duration of leisure time physical activity. This information can help guide efforts towards the most vulnerable groups since physical inactivity is associated with different diseases and even premature death.

DESCRIPTORS: Motor Activity. Leisure Activities. Regression Analysis. Models, Statistical. 


\section{INTRODUCTION}

Most biological parameters and medical conditions - for example, body mass index, blood pressure, and physical activity - are originally measured on a continuous scale. If the outcomes are continuous, some type of categorisation is commonly adopted decided based on other studies. These include internationally used cut-off points or data distributions, such as medians, quartiles, and plus or minus one or two standard deviations from the mean ${ }^{3}$. This strategy can lead to classification errors, especially for subjects that are borderline between cut-off points, thus decreasing the value of the data originally collected ${ }^{3,20}$. While information loss resulting from the process of categorisation or dichotomisation can lead to similar individuals being allocated to different groups, conversely, strata considered homogeneous may comprise markedly different individuals ${ }^{4,14}$. Furthermore, when using continuous data, it is essential to study the statistical distribution of the variable, which often diverges from the normal distribution. On the other hand, some variables are, in their origin, a mix between yes and no response, and for those who answer yes to the first question, further information is required.

In this study, leisure time physical activity was used as an example of this behaviour, as covariates associated with doing some physical versus no activity and the amount of time spent is a continuous measurement often categorised; our interest is not only in the dichotomous response (physical activity versus no physical activity), but also in the weekly duration. The usual threshold recommended - a minimum of 150 minutes/week in order to yield beneficial health impacts ${ }^{7,16}$ - can be difficult to achieve, and a better understanding of which covariates are associated with the increase of even a few minutes per week might be useful from a population point of view ${ }^{19}$.

Physical inactivity may have been responsible for some 5.3 million of the 57 million deaths recorded worldwide, in $2008^{11}$, and affected the occurrence of chronic noncommunicable diseases 9 . In Brazil, the frequency of individuals doing the equivalent of 150 minutes of moderate physical activity per week in 2014 was $35 \%$ a Given its importance to health and wellbeing, it is appropriate to seek to understand the conditions that facilitate (or hinder) leisure time physical activity and affect its weekly duration. Appropriate statistical methods that help understand this configuration of factors can contribute to policy making and interventions to foster this habit.

Studies of the practice of leisure time physical activity generally find persons who exercise regularly and others who do not exercise. In addition, the weekly duration of such activities varies greatly. Accordingly, the distribution of total time spent on leisure time physical activity tends to be non-negative and right-skewed, in addition to displaying excess zeros (persons who do no physical activity). This type of data, known as semi-continuous or zero-inflated data, is common in research in various fields. The commonest approach to modelling this type of distribution is to categorise the variable into two or three groups and to fit logistic or multinomial regression models ${ }^{8,15}$. However, as the variable is primarily continuous, it is possible that important information may be lost in the process of categorisation ${ }^{3}$. One alternative is to construct a two-part model: one considering the likelihood of an individual engaging in leisure time physical activity regularly or not exercising at all, while the other considers the duration of such activity. This can be done using a mixed model, which combines a binomial distribution and a continuous distribution, which is in this case the gamma distribution ${ }^{10}$. This approach can be called the zero-inflated gamma (ZIG) model. As the value zero can only come from the binomial distribution (the gamma distribution is asymmetrical and strictly positive), the factoring of the likelihood allows the model to be fitted separately. These models are known as two-part or "hurdle" models, in which zeros and non-zeros are considered as two independent processes ${ }^{13}$.

This study aimed to compare two methodological approaches: the multinomial model and the zero-inflated gamma model, evaluating the factors associated with the practice and amount of time spent on leisure time physical activity. 


\section{METHODS}

\section{The ELSA-Brasil Study}

The study population comprised the 2008-2010 baseline participants of the Estudo Longitudinal de Saúde do Adulto (Longitudinal Study of Adult Health, ELSA-Brasil), a multicentre cohort study involving civil servants from six teaching and research institutions in different cities in Brazil, whose main objectives were to estimate the incidence of cardiovascular diseases and diabetes and the main social, environmental, occupational, and biological determinants of the participants. Details of the study can be found in other publications ${ }^{2,21}$.

The 2008-2010 study baseline comprised 15,105 retired and active civil servants aged from 35 to 74 years. Of those, our analyses in this study included 14,823 participants with complete data on all the variables of interest.

Regular leisure time physical activity was measured using the leisure time physical activity module of the International Physical Activity Questionnaire (IPAQ) 5 . The questions cover the weekly frequency and duration of walking and moderate- or vigorous-intensity physical activities engaged in for 10 minutes at least during leisure time. For purposes of analysis, an approximate mean for the regularity of the leisure time physical activity was obtained by multiplying the number of days when physical activity was done by its duration in minutes.

To evaluate the two approaches we used the following covariables: gender, age (in years), education level (basic education, high school, college, graduate), and annual per capita family income, calculated as the midpoint of the net income category reported divided by the number of persons dependent on that income. In order to facilitate interpretation of the coefficients of the models, age was recorded in 10-year units and annual per capita family income in US $\$ 1,000$.

\section{Statistical Analysis}

Two approaches were used: the multinomial model, which is applied when the outcome is categorical with more than two levels, and the zero-inflated gamma model, which considers the variable in its original form. For the first approach, the measure of association estimated for each independent variable was the odds ratio and, for the second one, in addition to odds ratios, mean differences in time spent on leisure time physical activity were also estimated.

\section{Multinomial model}

For the multinomial model, the categorisation used was: no leisure time physical activity, less than 150 minutes/week, and 150 minutes/week or more (cut-off point recommended recently for promoting and maintaining adult health $)^{7,16}$. Physical inactivity was taken as the reference category.

\section{Zero-inflated gamma model}

Using this model, both facts can be contemplated: that various factors influence the decision to do, or not to do, leisure time physical activity and that the time devoted to leisure time physical activity may be associated with different factors. Let $Y_{\mathrm{i}}$ be total time, in minutes per week, spent on leisure time physical activity by individual $i$, and $X_{\mathrm{i}}$, a binary variable with binomial distribution, with $X_{\mathrm{i}}=1$ indicating that the individual $i$ does leisure time physical activity and $X_{\mathrm{i}}=0$, no leisure time physical activity. Thus, $P\left(X_{\mathrm{i}}=1\right)=p_{\mathrm{i}}$, where $p_{\mathrm{i}}$ is the probability of individual $i$ doing leisure time physical activity. If a given individual practices leisure time physical activity, its duration will be modelled using a gamma distribution with mean $\mu_{\mathrm{i}}$ and variance $\mu_{\mathrm{i}}^{2} v^{2}$. The likelihood function of the model is given by:

$$
L(p, \mu, v)=L(p) L(\mu, v)=\left[\prod_{Y_{i}=0}\left(1-p_{i}\right) \prod_{Y_{i}>0}\left(p_{i}\right)\right]\left[\prod_{Y_{i}>0} f\left(y_{i} \mid \mu_{i} v\right)\right]
$$

This factoring of the likelihood allows the models to be fitted separately. In order to model the probability of doing leisure time physical activity, $p_{\mathrm{i}}$, we used a logistic regression such 
that $\operatorname{logit}\left(p_{\mathrm{i}}\right)=x_{\mathrm{i}}^{\prime} \alpha$, where $x_{\mathrm{i}}$ represents the covariables and $\alpha$, the respective parameters. In order to model the duration of leisure time physical activity, we used a gamma regression. The inverse function is the canonical link function of a gamma distribution in a generalized linear mode $l^{10}$. However, the coefficients are difficult to interpret. As an alternative, this study used the identity link function, such that $\mu_{\mathrm{i}}=w_{\mathrm{i}} \beta$, making the coefficients easy to interpret. The combination of these two parts of the model, as set out in equation 1 , yields a zero-inflated gamma (ZIG) distribution. Note that the covariables used in each part of the model are not necessarily the same. The analyses were performed using software $\mathrm{R}$ version 3.2.2 ${ }^{17}$.

\section{Ethical Considerations}

The study was approved by the National Research Ethics Commission (CONEP - 976/2006) and by the Research Ethics Committee of each institution. All participants signed an informed consent form.

\section{RESULTS}

Mean age of participants was 52 years (with standard deviation of 9.1 years), $54.4 \%$ were women, $36.8 \%$ had graduate education, and mean annual per capita income was US\$6,505. Of the participants, 6,369 (43\%) did no leisure time physical activity and, among those who did, mean time spent on leisure time physical activity was 237 minutes/week. As shown in the Figure, the distribution of the duration of leisure time physical activity is quite skewed, as it displays excess zeros, and only a few participants reported doing more than 1,000 minutes of leisure time physical activity per week. Physical inactivity was reported more frequently by women (48.0\%), participants with lower education level (55.4\%), and the group with lower mean age and per capita income. Men who did engage in physical activity on average spend more time than women. We did not observe a clear gradient between education level and total time spent on physical activity (Table 1).

Table 2 shows the odds ratios estimated from the multinomial model and the logistic part of the zero-inflated gamma model, as well as the coefficients estimated by gamma regression and their 95\% confidence intervals. The variables age, gender, and per capita income were significant in all the models. In the multinomial model, at each 10-year increase in the age of participants, the adjusted odds of doing leisure time physical activity for more than 150 minutes/week and up to 150 minutes/week increased 1.14 and 1.07 times, respectively. This type of estimate was obtained for each of the other variables of interest.

In addition to the information that men are $70 \%$ more likely to engage in leisure time physical activity than women, the ZIG model also informed that, among the participants who did leisure time physical activity, after adjusting for age, education level, and income, men exercised for a mean 28 minutes more per week than women. The logistic part and multinomial model returned a gradient in which the higher the education level, the greater

Table 1. Total time spent on physical activity by population characteristics. ELSA-Brasil, 2008-2010.

\begin{tabular}{lccccc}
\hline \multirow{2}{*}{ Variable } & \multirow{2}{*}{} & \multicolumn{4}{c}{ Physical activity (min/week) } \\
\cline { 3 - 6 } & & $\mathbf{n o}$ & $\mathbf{1 5 0}$ & $\mathbf{1 5 0}$ & Total time spent \\
\hline Mean age (years) & - & 51.5 & 52.3 & 52.8 & - \\
Mean annual per capita income (US\$) & - & $5,318.30$ & $6,903.11$ & $7,703.00$ & - \\
Gender & & & & & \\
$\quad$ Women & 8,061 & 48.0 & 20.5 & 31.5 & 224.7 \\
$\quad$ Men & 6,762 & 36.9 & 23.0 & 40.1 & 249.0 \\
Education level & & & & & \\
$\quad$ Basic & 1,884 & 55.4 & 20.2 & 24.4 & 220.3 \\
$\quad$ High school & 5,125 & 51.9 & 19.5 & 28.6 & 233.9 \\
$\quad$ College & 2,351 & 30.5 & 24.4 & 45.2 & 242.8 \\
$\quad$ Graduate & 5,463 & 42.5 & 21.3 & 36.2 & 240.5 \\
\hline
\end{tabular}


Table 2. Results of the multinomial and zero-inflated gamma models for total time spent on physical activity. ELSA-Brasil, $2008-2010$.

\begin{tabular}{|c|c|c|c|c|}
\hline \multirow{3}{*}{ Variable } & \multicolumn{2}{|c|}{ Multinomial $^{\mathbf{a}}$} & \multicolumn{2}{|c|}{ Zero-inflated gamma } \\
\hline & $<150 \mathrm{~min} /$ week & $\geq 150 \mathrm{~min} /$ week & Logistic $^{\mathbf{a}}$ & Gamma $^{\text {b }}$ \\
\hline & OR $(95 \% \mathrm{Cl})$ & OR $(95 \% \mathrm{Cl})$ & OR $(95 \% \mathrm{Cl})$ & Coeff. $(95 \% \mathrm{Cl})$ \\
\hline Age in 10-year intervals & $1.07(1.06-1.09)$ & $1.14(1.13-1.15)$ & $1.12(1.07-1.16)$ & $6.20(1.47-10.97)$ \\
\hline \multicolumn{5}{|l|}{ Gender } \\
\hline Men & $1.54(1.41-1.68)$ & $1.81(1.67-1.95)$ & $1.70(1.58-1.82)$ & $28.78(20.24-37.35)$ \\
\hline \multicolumn{5}{|l|}{ Education level } \\
\hline High school & $1.11(0.99-1.24)$ & $1.41(1.26-1.58)$ & $1.28(1.14-1.43)$ & $19.93(4.68-34.62)$ \\
\hline College & $1.40(1.22-1.60)$ & $2.00(1.75-2.28)$ & $1.72(1.51-1.97)$ & $25.81(8.30-43.09)$ \\
\hline Graduate & $1.87(1.65-2.12)$ & $2.69(2.38-3.05)$ & $2.32(2.04-2.63)$ & $14.45(-1.57-29.93)$ \\
\hline Annual per capita income in US\$1000 & $1.04(1.03-1.05)$ & $1.06(1.05-1.06)$ & $1.05(1.04-1.06)$ & $7.58(2.91-20.50)$ \\
\hline
\end{tabular}

a Reference category - does no physical activity.

b Significance of parameters evaluated compared with zero value.

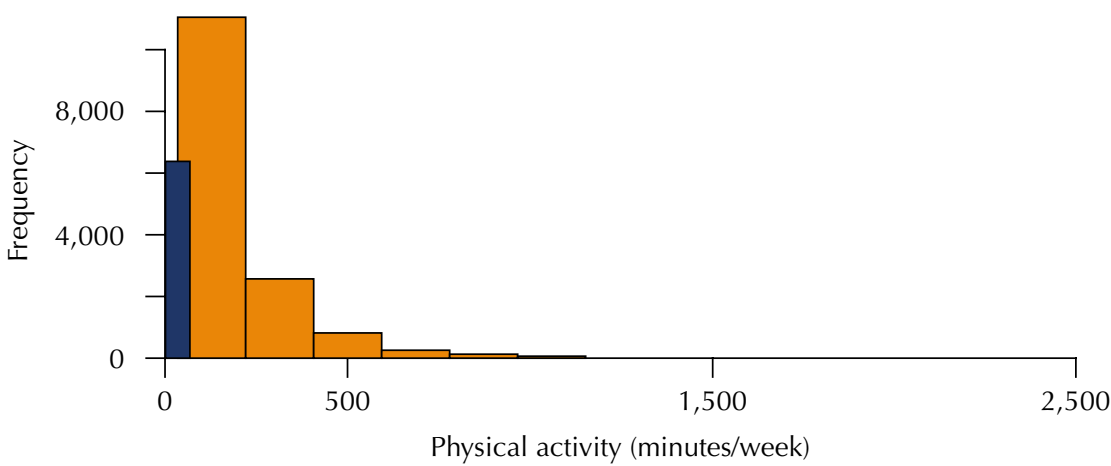

Figure. Histogram of the distribution of total time spent on physical activity by participants in ELSA-Brasil, 2008-2010.

the likelihood of doing leisure time physical activity. Even though that gradient was not observed in the gamma part of the ZIG model, the coefficients for education at the levels of high school and college are significant and suggest more time spent on leisure time physical activity as compared with participants who had only basic education. At each US $\$ 1,000$ increase in the participants' annual per capita income, the adjusted likelihood of doing leisure time physical activity was 1.05 times greater and they approximately spent a mean of seven minutes more per week on leisure time physical activity. Similar results were found in the multinomial model; the adjusted odds of doing leisure time physical activity for more than 150 minutes/week and up to 150 minutes/week increased 1.06 and 1.04 times, respectively.

\section{DISCUSSION}

In this application, the analysis of the time spent on leisure time physical activity demonstrated the usefulness of the gamma distribution for fitting outcomes that are primarily continuous and skewed. The presence of zeros, which in this case indicate physical inactivity, led us to construct a model that combined the gamma and binomial distributions. As the weekly duration of leisure time physical activity has an important protective effect with regard to numerous health outcomes, it is extremely important to be able to discover not only whether or not leisure time physical activity is done, but also some of the main determinants of the duration of such leisure time physical activity for public health purposes 9 . The multinomial model estimates only the probability of leisure time physical activity being done, by category of variable, as compared with "not being done", for example ${ }^{10}$. In that type of strategy, the mean time spent on the activity (in minutes per week) cannot be estimated by converting time spent on leisure time physical activity into a categorical variable. That is the main advantage of using the zero-inflated gamma model. On the other hand, investigators have postulated that even lower levels of physical activity may be associated with health benefits ${ }^{24}$. This dose-response relationship is more easily captured by the multinomial model. 
The two-part regression model, in which zeros may occur in only one of the parts, is a simple and statistically valid methodology to analyse skewed data with zeros. Ribeiro et al. ${ }^{18}$, in their study of leisure time physical activity, has divided the research question into two components: participation in and time spent on leisure time physical activity. However, the weekly duration of leisure time physical activity has been modelled by means of a normal distribution, which is a symmetric probability distribution and generally does not correspond to the distribution of leisure time physical activity. In our approach using gamma distribution, the models were separated by factoring the likelihood.

With the ZIG model, the variables that are associated with the outcome in each part of the model can be different. For example, in our study, only the participants with high school and college education displayed significant increases in time spent on leisure time physical activity compared with participants who had only basic schooling. Meanwhile, the decision to practice or not leisure time physical activity was associated with all education levels. In addition, by using the identity link function in the gamma regression, we could interpret the model parameters directly ${ }^{12}$. For example, men exercised, on average, 28 minutes/week more than women.

The use of questionnaires to assess physical activity, including the IPAQ, is an imprecise method. The time spent on physical activity is usually overestimated and has been recently replaced by objective measures ${ }^{6,23}$. As the focus of the article was to compare models based on the same data set, limitations related to data acquisition do not affect the conclusions. Usual model comparison criteria such as Akaike information criterion (AIC) ${ }^{1}$ and Bayesian information criterion (BIC) ${ }^{22}$ were not used because they do not exactly model the same response variable.

We consider that the ZIG model, which is rarely used in epidemiological studies, can offer more appropriate answers in a variety of situations. The models fitted in this study gave substantial information on the problem of physical inactivity, making it possible to quantify the association with important variables, such as gender, age, education level, and income. Given that physical inactivity is associated with different diseases and even premature death, this information can help direct efforts and policies towards the most vulnerable groups. In that regard, the emphasis should be on the most sedentary - a group comprising young women with low education level and income.

\section{REFERENCES}

1. Akaike $\mathrm{H}$. A new look at the statistical model identification. IEEE Tans Automat Contr. 1974;19(6):716-23. https://doi.org/10.1109/TAC.1974.1100705

2. Aquino EML, Barreto SM, Bensenor IM, Carvalho MS, Chor D, Duncan BB, et al. Brazilian Longitudinal Study of Adult Health (ELSA-Brasil): objectives and design. Am J Epidemiol. 2012;175(4):315-24. https://doi.org/10.1093/aje/kwr294

3. Bennette C, Vickers A. Against quantiles: categorization of continuous variables in epidemiologic research, and its discontents. BMC Med Res Methodol. 2012;12:21. https://doi.org/10.1186/1471-2288-12-21

4. Dawson NV, Weiss R. Dichotomizing continuous variables in statistical analysis: a practice to avoid. Med Decis Making. 2012;32(2):225-6. https://doi.org.br/10.1177/0272989X12437605

5. Hallal PC, Victora CG. Reliability and validity of the International Physical Activity Questionnaire (IPAQ). Med Sci Sports Exerc. 2004;36(3):556.

6. Hartley S, Garland S, Young E, Bennell KL, Tay I, Gorelik A, Wark JD. A comparison of self-reported and objective physical activity measures in young Australian women. JMIR Public Health Surveill. 2015;1(2):e14. https://doi.org/10.2196/publichealth.4259

7. Haskell WL, Lee IM, Pate RR, Powell KE, Blair SN, Franklin BA, et al. Physical activity and public health: updated recommendation for adults from the American College of Sports Medicine and the American Heart Association. Med Sci Sports Exerc. 2007;39(8):1423-34. https://doi.org/10.1249/mss.0b013e3180616b27 
8. Jurj AL, Wen W, Gao YT, Matthews CE, Yang G, Li HL, et al. Patterns and correlates of physical activity: a cross-sectional study in urban Chinese women. BMC Public Health. 2007;7:213. https://doi.org/10.1186/1471-2458-7-213

9. Kivimäki M, Nyberg ST, Batty GD, Fransson El, Heikkilä K, Alfredsson L, et al. Job strain as a risk factor for coronary heart disease: a collaborative meta-analysis of individual participant data. Lancet. 2012;380(9852):1491-7. https://doi.org/10.1016/S0140-6736(12)60994-5

10. Lee AH, Zhao Y, Yau KKW, Xiang L. How to analyze longitudinal multilevel physical activity data with many zeros? Prev Med. 2010;51(6):476-81. https://doi.org/10.1016/j.ypmed.2010.09.012

11. Lee IM, Shiroma EJ, Lobelo F, Puska P, Blair SN, Katzmarzyk PT. Effect of physical inactivity on major non-communicable diseases worldwide: an analysis of burden of disease and life expectancy. Lancet. 2012;380(9838):219-29. https://doi.org/10.1016/S0140-6736(12)61031-9

12. McCullagh P, Nelder JA. Generalized linear models. 2.ed. Boca Raton: Chapman \& Hall/CRC; 1989. (Monograph on Statistics and Applied Probability, 37).

13. Mullahy J. Specification and testing of some modified count data models. J Econom. 1986;33(3):341-65. .https://doi.org/10.1016/0304-4076(86)90002-3

14. Naggara O, Raymond J, Guilbert F, Roy D, Weill A, Altman DG. Analysis by categorizing or dichotomizing continuous variables is inadvisable: an example from the natural history of unruptured aneurysms. AJNR Am J Neuroradiol. 2011;32(3):437-40. https://doi.org/10.3174/ajnr.A2425

15. Nitzan-Kaluski D, Demem-Mazengia G, Shimony T, Goldsmith R, Berry EM. Prevalence and determinants of physical activity and lifestyle in relation to obesity among schoolchildren in Israel. Public Health Nutr. 2009;12(6):774-82. https://doi.org/10.1017/S1368980008002991

16. O'Donovan G, Blazevich AJ, Boreham C, Cooper AR, Crank H, Ekelund U, et al. The ABC of Physical Activity for Health: a consensus statement from the British Association of Sport and Exercise Sciences. J Sports Sci. 2010;28(6):573-91. https://doi.org/10.1080/02640411003671212

17. R Development Core Team. R: a language and environment for statistical computing. Vienna: R Foundation for Statistical Computing; 2015 [cited 2017 Mar 10]. Available from: http://www.r-project.org/

18. Ribeiro Al, Pires A, Carvalho MS, Pina MF. Distance to parks and non-residential destinations influences physical activity of older people, but crime doesn't: a cross-sectional study in a southern European city. BMC Public Health. 2015;15:593. https://doi.org/10.1186/s12889-015-1879-y

19. Rose G. Sick individuals and sick populations. Int J Epidemiol. 1985;14(1):32-8. https://doi.org/10.1093/ije/14.1.32

20. Rothman KJ, Greenland S, Lash TL. Modern epidemiology. 3.ed. Philadelphia: Lippincott Williams \& Wilkins, 2008.

21. Schmidt MI, Duncan BB, Mill JG, Lotufo PA, Chor D, Barreto SM, et al. Cohort Profile: Longitudinal Study of Adult Health (ELSA-Brasil). Int J Epidemiol. 2015;44(1):68-75. https://doi.org/10.1093/ije/dyu027

22. Schwarz G. Estimating the dimension of a model. Ann Stat.1978;6(2):461-4. https://doi.org/10.1214/aos/1176344136

23. Steene-Johannessen J, Anderssen SA, Van der Ploeg HP, Hendriksen IJM, Donnelly AE, Brage $\mathrm{S}$, et al. Are self-report measures able to define individuals as physically active or inactive? Med Sci Sports Exerc. 2016;48(2):235-44. https://doi.org/10.1249/MSS.00000000000007

24. Warburton DE, Nicol CW, Bredin SS. Health benefits of physical activity: the evidence. CMAJ. 2006;174(6): 801-9. https://doi.org/10.1503/cmaj.051351

Funding: The ELSA-Brasil baseline study was supported by the Brazilian Ministry of Health (Department of Science and Technology) and Ministry of Science and Technology (Study and Project Funding agency - FINEP and National Research Council - CNPq) (Grants 01060010.00 RS, 01060212.00 BA, 01060300.00 ES, 0106 0278.00 MG, $01060115.00 \mathrm{SP}$, and $01060071.00 \mathrm{RJ}$ ). The funding source had no influence over the study design, the data collection, analysis, and interpretation, the writing of the paper, or the decision to publish.

Authors' Contribution: Analysis and interpretation of the data: AAN, MSC, DC. Preparation and writing of the study: AAN, MSC, RHG, DC. Critical review of the study: AAN, MSC, RHG, MJMF, ECPM, ISS, DC. All authors participated in the approval of the final version of the study to be published.

Conflict of Interest: The authors declare no conflict of interest. 